\title{
Habitat Characteristics as Potential Drivers of the Angiostrongylus daskalovi Infection in European Badger (Meles meles) Populations
}

\author{
Eszter Nagy ${ }^{1}$, Ildikó Benedek ${ }^{2}$, Attila Zsolnai ${ }^{2}$ (D) Tibor Halász ${ }^{3,4}$, Ágnes Csivincsik ${ }^{3,5}$, Virág Ács ${ }^{3}$ (D) \\ Gábor Nagy ${ }^{3,5, *}$ and Tamás Tari ${ }^{1}$ \\ 1 Institute of Wildlife Management and Wildlife Biology, Faculty of Forestry, University of Sopron \\ H-9400 Sopron, Hungary; nagy.gesztenye07@gmail.com (E.N.); tari.tamas@uni-sopron.hu (T.T.) \\ 2 Institute of Animal Breeding, Kaposvár Campus, Hungarian University of Agriculture and Life Sciences, \\ H-7400 Kaposvár, Hungary; ildiko.benedek@uni-mate.hu (I.B.); attila.zsolnai@gmail.com (A.Z.) \\ 3 Institute of Physiology and Animal Nutrition, Kaposvár Campus, Hungarian University of Agriculture and \\ Life Sciences, H-7400 Kaposvár, Hungary; halasz.tibor@sefag.hu (T.H.); csivincsik.agnes@uni-mate.hu (Á.C.); \\ acs.virag@uni-mate.hu (V.Á.) \\ 4 Somogy County Forest Management and Wood Industry Share Co., H-7400 Kaposvár, Hungary \\ 5 One Health Working Group, Kaposvár Campus, Hungarian University of Agriculture and Life Sciences, \\ H-7400 Kaposvár, Hungary \\ * Correspondence: gabor.nagy.oh@gmail.com
}

check for updates

Citation: Nagy, E.; Benedek, I.; Zsolnai, A.; Halász, T.; Csivincsik, Á.; Ács, V.; Nagy, G.; Tari, T. Habitat Characteristics as Potential Drivers of the Angiostrongylus daskalovi Infection in European Badger (Meles meles) Populations. Pathogens 2021, 10, 715. https://doi.org/10.3390/ pathogens 10060715

Academic Editor: Stefania Perrucci

Received: 23 April 2021

Accepted: 3 June 2021

Published: 7 June 2021

Publisher's Note: MDPI stays neutral with regard to jurisdictional claims in published maps and institutional affiliations.

Copyright: (c) 2021 by the authors. Licensee MDPI, Basel, Switzerland. This article is an open access article distributed under the terms and conditions of the Creative Commons Attribution (CC BY) license (https:// creativecommons.org/licenses/by/ $4.0 /)$.

\begin{abstract}
From 2016 to 2020, an investigation was carried out to identify the rate of Angiostrongylus spp. infections in European badgers in Hungary. During the study, the hearts and lungs of 50 animals were dissected in order to collect adult worms, the morphometrical characteristics of which were used for species identification. PCR amplification and an 18S rDNA-sequencing analysis were also carried out. Global and local spatial autocorrelation methods were used to detect high-rated and low-rated infected animal clusters. We conducted a binary logistic regression analysis along with hierarchical agglomerative clustering to determine the relation between selected biotic and abiotic variables, and the prevalence of an $A$. daskalovi infection. We found a high prevalence (72\%) and moderate mean intensity (14.1) of Angiostrongylus sp. infection. Morphology and sequencing revealed that all animals were infected by $A$. daskalovi. The results of both spatial autocorrelations suggested that the spatial distribution of infected badgers was more spatially clustered than random. The results of an analysis of the correlation between habitat characteristics and infection showed that the infected animals could be associated with dry and open landscape habitats without extended and connected canopy. It is suggested that the territorial behaviour of badgers and the landscape-directed aggregation of potential intermediate hosts might be the drivers of an $A$. daskalovi infection.
\end{abstract}

Keywords: European badger; Meles meles; Angiostrongylus daskalovi; Hungary

\section{Introduction}

Members of the Angiostrongylus genus, which belongs to the Metastrongyloidea superfamily, often referred to as "lungworms", may cause severe symptoms in the infected hosts [1]. During their life cycle, they can be found in different definitive hosts, e.g., carnivores, rodents or tupaniids, and in intermediate hosts such as slugs and aquatic or terrestrial snails. In some cases, paratenic hosts may also be involved. First-stage larvae are excreted via faeces and infect the gastropods by ingestion or penetration. In intermediate hosts, the larvae develop into third-stage or infective larvae. Definitive hosts become infected by ingestion of gastropods or their slime [2]. To our present knowledge, out of 22 Angiostrongylus species, 6 have been described as infective for carnivores. Of these 22 species, Angiostrongylus felineus, Angiostrongylus gubernaculatus and Angiostrongylus raillieti, are known in the Americas. Angiostrongylus chabaudi and Angiostrongylus daskalovi are 
widespread exclusively on the European continent, while Angiostrongylus vasorum also has been isolated in the Americas, Australia and certain parts of Africa. In mustelid species, both $A$. vasorum and $A$ daskalovi occur [3-6].

A. daskalovi is a cardiopulmonary parasite of the carnivore taxa, Mustelidae family [4]. The very first report of this nematode dates back to the late 1980s in Bulgaria, where the worm was collected from European badgers (Meles meles), European pine martens (Martes martes) and beech martes (Martes foina) [7]. Since that time, the presence of the A. daskalovi has been confirmed in two other countries, Spain, and Romania [8,9]. The parasite populates the lung arteries and the heart's right ventricle [8]. In previous studies, the prevalence of the $A$. daskalovi infection ranged from $16.95-37.5 \%$, while little is known about the mean intensity (Table 1).

Table 1. Characteristics of $A$. daskalovi Infection in Europe.

\begin{tabular}{ccccc}
\hline Badgers Examined & Badgers Infected & Prevalence (\%) & Mean Intensity & Reference \\
\hline 59 & 10 & 16.95 & 4.7 & {$[7]$} \\
50 & 12 & 24 & NA & {$[8]$} \\
8 & 3 & 37.5 & NA & {$[9]$} \\
11 & 2 & 18.18 & NA & {$[10]$} \\
\hline
\end{tabular}

In Hungary from 2009 to 2019, the average number of badgers shot or found dead was 9199 annually. The increase in this number in the past 3 years-10,347 in 2018, 12,394 in 2019, and 16,635 in 2020 - indicates the increase of the badger population (National Game Management Database, http:/ / www.ova.info.hu/vgstat.html (accessed on 21 February 2021). Despite this rapid rise of population, only one study with a small sample size was conducted to investigate the parasitological state of the badger population. However, neither the presence of $A$. daskalovi nor that of $A$. vasorum was confirmed [11]. Considering the increase of the definitive host population in Hungary and based on the fact that few adequate data are available on the European situation of the $A$. daskalovi, we carried out a monitoring of the densest mustelid population in southwest Hungary. Our main aim was to determine the biotic and abiotic factors, which may drive angiostrongylosis characteristics in badgers. Our further goal was to estimate the epidemiological risk of an expanding badger population on protected mustelids and companion animals.

\section{Results}

\subsection{Species Identification}

Among 50 badgers, we found 36 individuals with an Angiostrongylus sp. infection; thus, the calculated prevalence was $72 \%(C 195 \%=58.2-83.3 \%)$. The worm burden ranged from 1 to 97 specimens (mean intensity: 14.1; CI95\% = 10.3-23.2). Based on the observed morphological features, we revealed that all of the animals had an A. daskalovi infection and $A$. vasorum was not detected in any specimens (Figure 1). In addition to $A$. daskalovi, three further lungworm taxa (Crenosoma spp., Perostrongylus falciformis, Eucoeleus aerophilus) were observed in the specimens (see Table S1). 


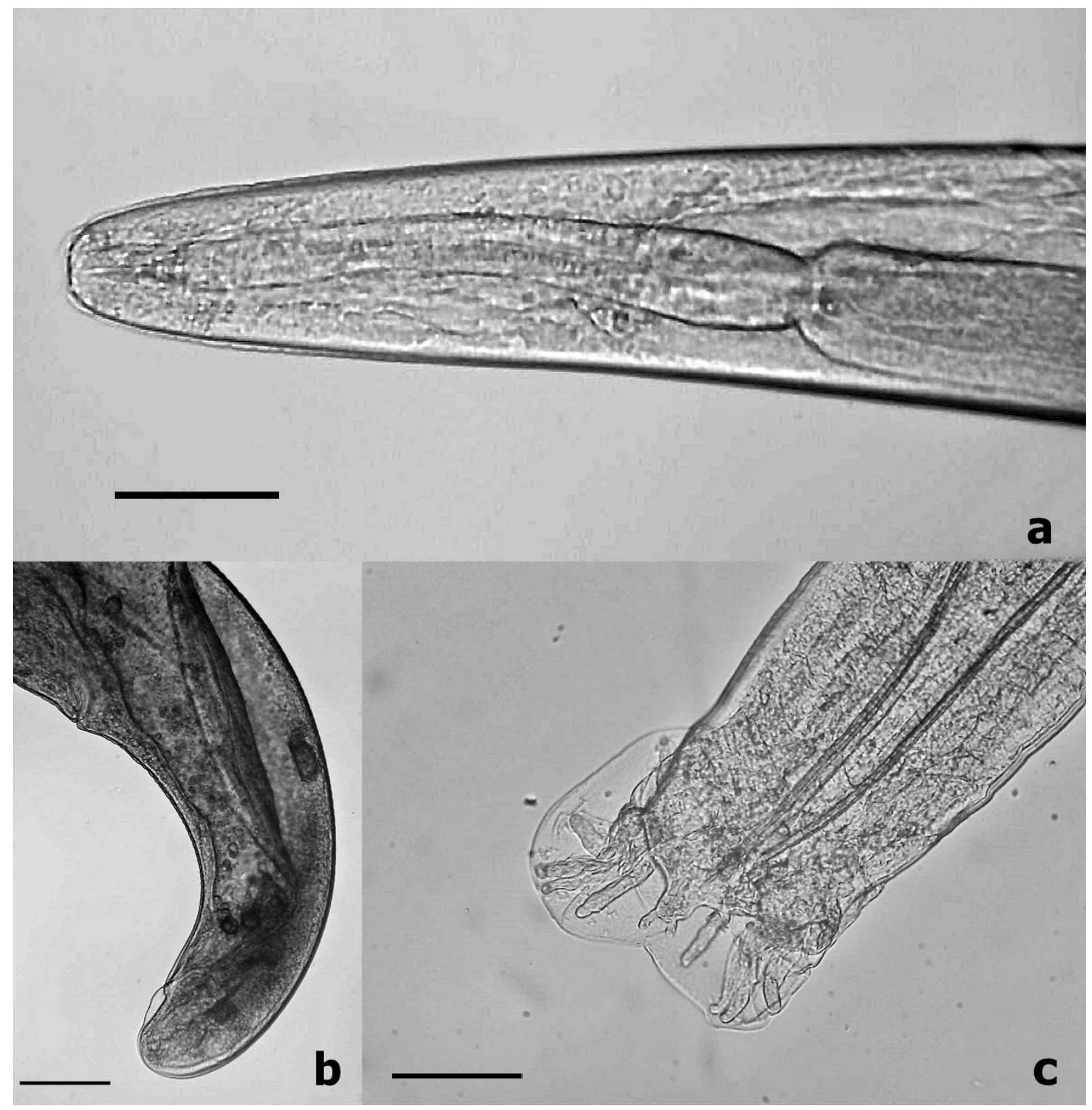

Figure 1. Morphological characteristics of $A$. daskalovi from a badger. The anterior part of the body (a), posterior part of a female (b), and the bursa copulatrix of a male (c), bar: $100 \mu \mathrm{m}$.

The sequences (GenBank accession no. MZ151311, MZ151312) obtained from two adult $A$. daskalovi males showed $99 \%$ of sequence identity. A phylogenetic analysis displayed A. daskalovi specimens blending into the clade, including several Angiostrongylus spp. sequences available in the GenBank database (Figure 2).

Of the infected 36 lung specimens, none showed macroscopically visible lesions of inflammation or other pathological changes (Figure 3). 


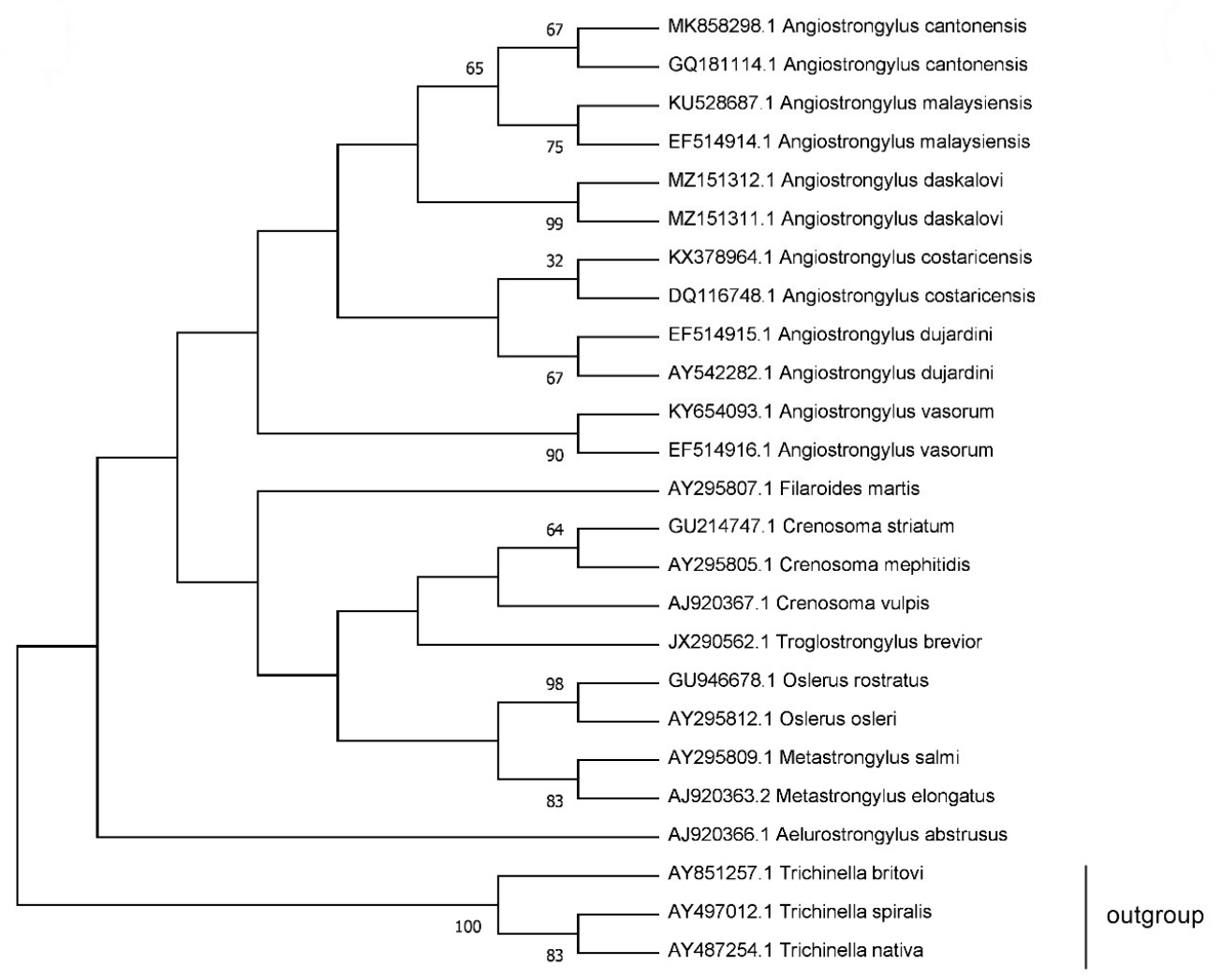

Figure 2. Relationship of A. daskalovi with members of the superfamily Metastrongyloidea found by18S rDNA sequencing. (The percentage of replicate trees, in which the associated taxa clustered together in the bootstrap test (50\% majority rule consensus with 1000 replicates) is shown next to the branches).

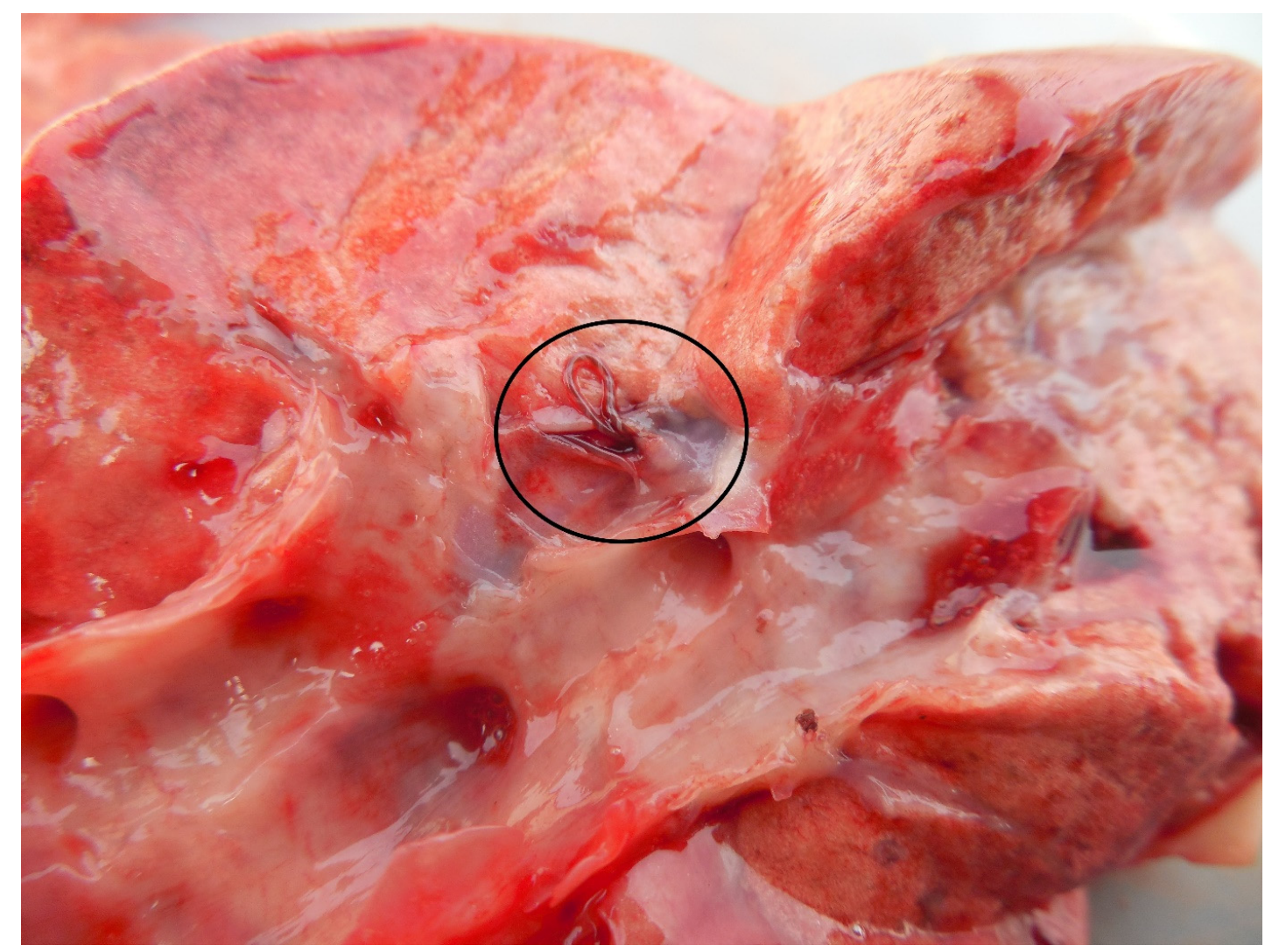

Figure 3. A. daskalovi specimen in an opened lung vessel. 


\subsection{Spatial Analysis}

We collected samples from 24 Universal Transverse Mercator (UTM) quadrates, of which 18 had infected badgers. The Moran's I (Moran's I $=0.061 ; \mathrm{z}=3.0304 ; p=0.0024$ ) indicated a positive global spatial autocorrelation for the $A$. daskalovi. The result suggested that the spatial distribution of the parasite infection was more spatially clustered than randomly. The Local Spatial Clustering (LSC) disclosed three local clusters (Figure 4). A high-rated cluster proved significant, whereas the two others did not show significance. The radius of the high-rated cluster $(p=0.009)$ was $7.85 \mathrm{~km}$ around the centre coordinate (46.188324 N, 17.737759 E). Out of 24 involved badgers, 23 animals were infected; thus, the relative risk proved 1.95 with a $7.47 \log$-likelihood ratio.

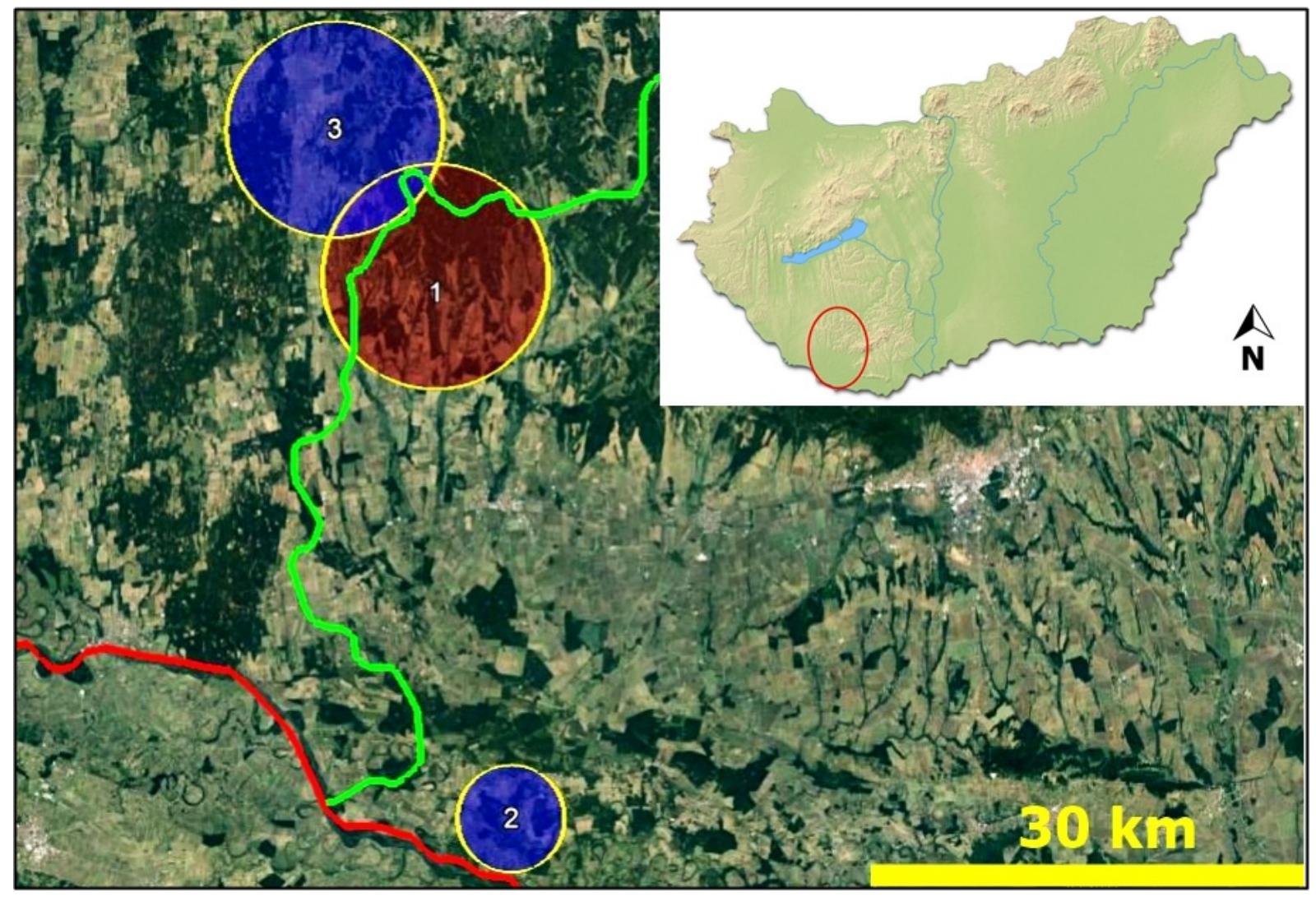

Figure 4. Local spatial clusters of the A. daskalovi infection (red = high-rated, significant cluster; blue = low-rated, nonsignificant cluster; green line $=$ county border; red line $=$ country border).

\subsection{Environmental Determinants of the A. daskalovi Infection}

For the A. daskalovi infection, nine variables were potential candidates for modelling infection/non-infection. The broad-leaved forest (BLF), precipitation (PREC) and temperature at $2 \mathrm{~m}$ in ${ }^{\circ} \mathrm{C}(\mathrm{T} 2 \mathrm{M})$ variables were rejected from the process because their variance inflation factors (VIF) value exceeded the tolerance threshold. The overall model was statistically significant compared to the null model $\left(\chi^{2}=12.416, p=0.006\right)$, and justified $31.18 \%$ of the variation of infection. It also correctly predicted $78.9 \%$ of cases. Our best regression model had a 0.79 area under the curve (AUC) score $(p=0.0013)$ and contained 3 explanatory variables, namely relative humidity at $2 \mathrm{~m}$ in \% (RH2M), mixed agricultural and forest area (MIX) and wetlands (WET) (Akaike's Information Criterion, AIC value 56.67). Their regression coefficients (B) suggested a negative relationship between these explanatory variables and the presence of the infection (Table 2).

By the hierarchical agglomerative clustering (HAC), the 36 infected badgers were divided into 3 main groups and a singleton sample (Figure 5). 
Table 2. Binary logistic regression for the A. daskalovi infection in badgers.

\begin{tabular}{|c|c|c|c|c|c|c|}
\hline \multirow{2}{*}{ Predictor } & \multirow{2}{*}{ B } & \multirow{2}{*}{ SD } & \multirow{2}{*}{$p$-Value } & \multirow{2}{*}{ OR } & \multicolumn{2}{|c|}{ OR CI95\% } \\
\hline & & & & & Lower & Upper \\
\hline RH2M & -2.704 & \pm 1.112 & 0.015 & 0.067 & 0.008 & 0.592 \\
\hline MIX & -0.016 & \pm 0.008 & 0.04 & 0.984 & 0.968 & 0.999 \\
\hline WET & -0.093 & \pm 0.049 & 0.056 & 0.911 & 0.828 & 1.002 \\
\hline CONSTANT & 199.01 & \pm 81.29 & 0.014 & $2.69 \times 10^{86}$ & & \\
\hline
\end{tabular}

(B = regression coefficient, $\mathrm{SD}=$ standard deviation, $\mathrm{OR}=$ odds ratio, OR CI95\% $=95 \%$ confidential interval of odds ratio, $\mathrm{RH} 2 \mathrm{M}=$ relative humidity at $2 \mathrm{~m}, \mathrm{MIX}=$ mixed agricultural and forest area, WET = wetlands).

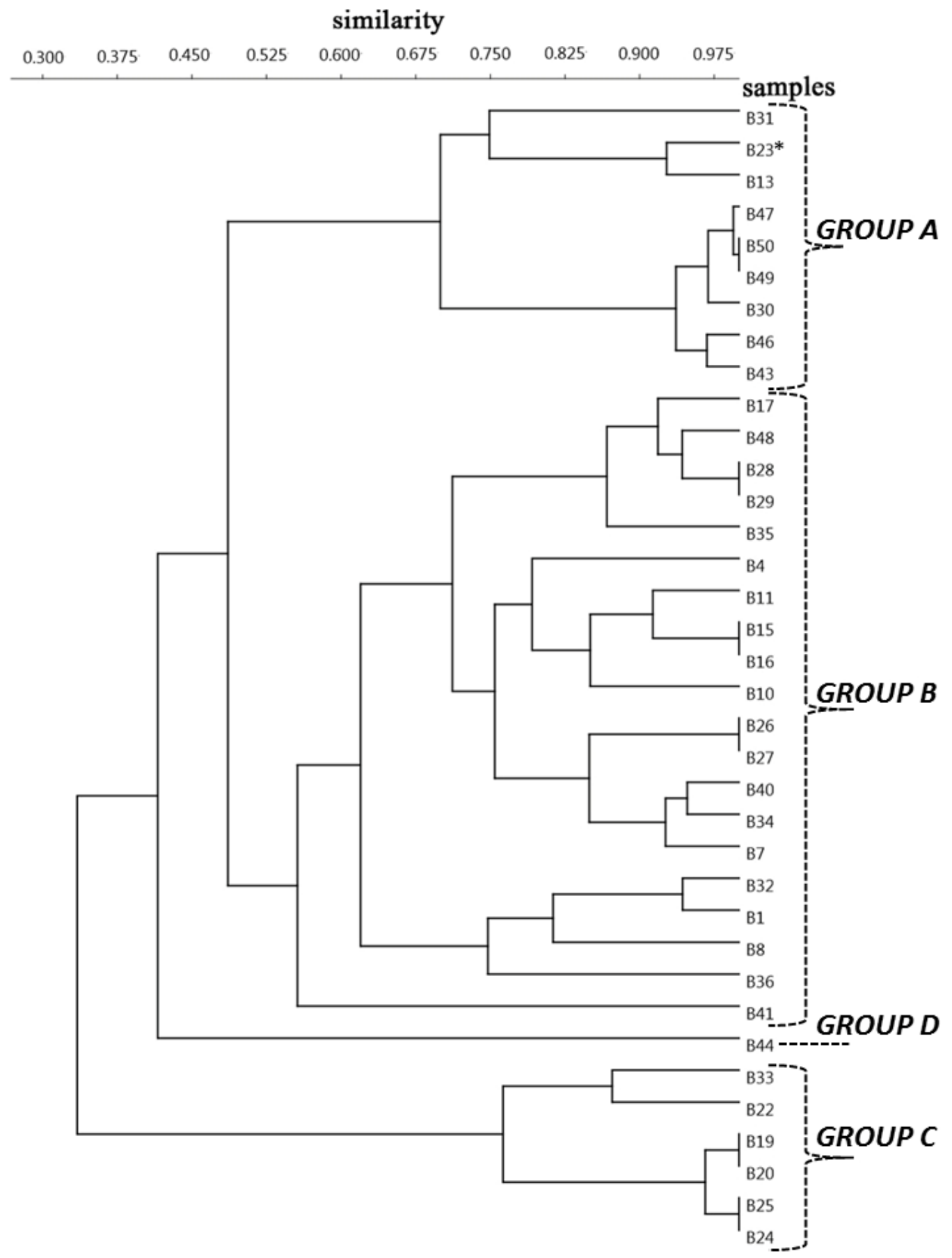

Figure 5. The result of a hierarchical agglomerative clustering analysis of the buffer zone of 36 infected badgers. ( ${ }^{*} \mathrm{~B} 23$ and other identification numbers indicate the infected animals). 
Based on similarity values of habitat types in the buffer zones, we determined the predominant habitat categories of different groups. The results showed that the highest proportions of BLF (74.14\%) were found in GROUP A. GROUP B was characterised as an agro-forest mosaic habitat with $42.75 \%$ BLF and $35.54 \%$ arable land (ARA). Grasslands (GRA, 70.65\%) dominated in GROUP C, while in GROUP D, the MIX (49.45\%) habitat type ruled (Figure 6). Because the last-mentioned group contained only one badger, we did not involve it in further analyses. The landcover difference of habitat types between the groups was confirmed statistically significant $(\mathrm{H}=10.95, p=0.004)$.

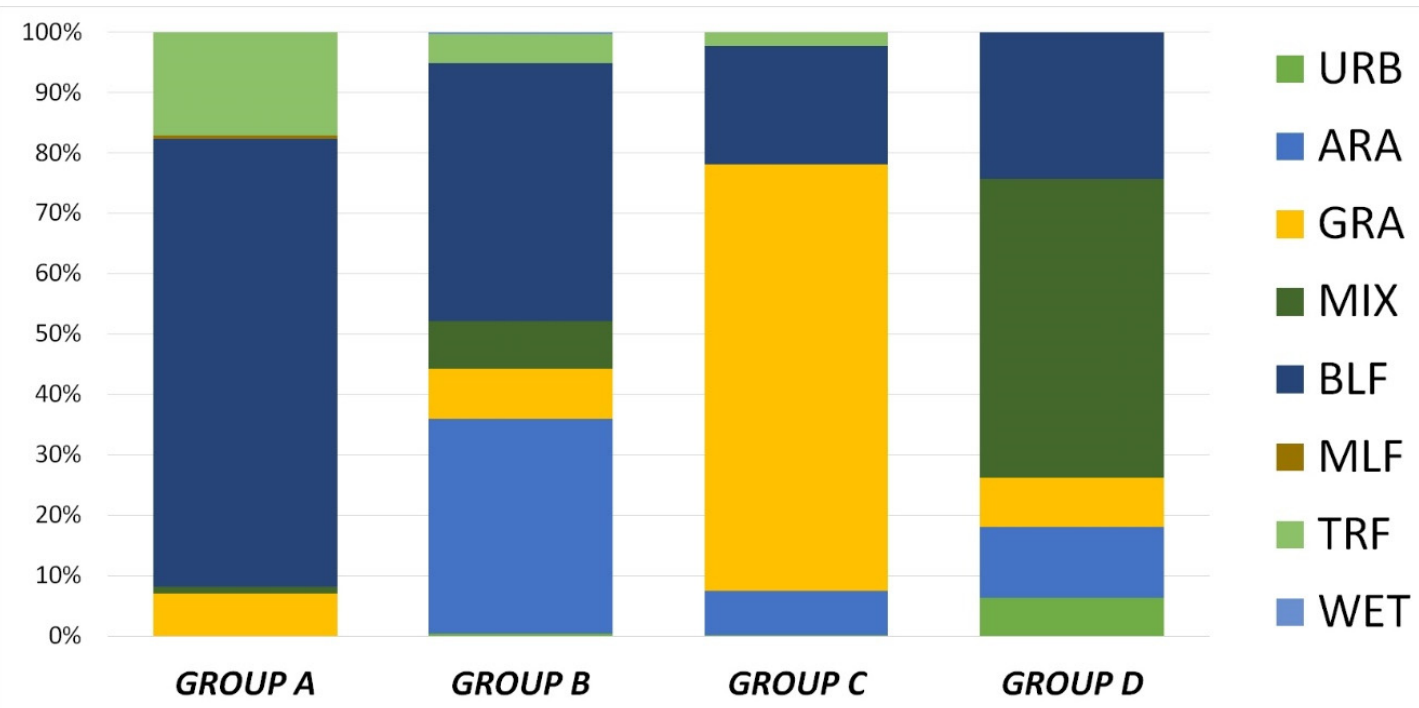

Figure 6. Differences of habitat types among groups were formed by hierarchical agglomerative clustering. (URB = urban area, $\mathrm{ARA}=$ arable land, GRA = grassland, MIX = mixed agricultural and forest area, BLF = broad-leaved forest, $\mathrm{MLF}=$ mixed forest, $\mathrm{TRF}=$ shrubland, $\mathrm{WET}=$ wetlands $)$.

In the forest-dominated GROUP A $(n=9)$, the intensity was 9.56 worms / badger. In the agro-forest mosaic structured GROUP B $(n=20)$, the average $A$. daskalovi number was 10.55 worms/badger. In the grassland-dominated GROUP C $(n=6)$, the average parasite number was 34.50 in the infected hosts. The Mann-Whitney pairwise comparison confirmed that the difference between GROUP A and GROUP B was not significant $(p=0.0619)$, while the habitat structure of GROUP C diverged from both GROUP A considerably $(p=0.008)$ and GROUP B $(p=0.002)$.

\section{Discussion}

Our study verified the presence of the A. daskalovi in badgers as a new nematode species in Hungary. We observed a surpassingly high prevalence and a moderate mean intensity in the southwestern Hungarian badger population. These results suggested a larger infection rate than observed in previous European surveys [7-11].

Our results may be explained by the dynamic increase of the host population. The larger host groups can result in more intense parasite infections [12]. Growing badger density increases the number of first-stage larvae in the environment, thus in the gastropod intermediate hosts. Finally, this process can promote an elevated parasite prevalence in the host population.

We supposed that the difference in the observed mean intensity is associated with the habitat types, which could influence the feeding habits of badgers. In grassland-dominated habitats, the relevant direct or indirect (with plant parts) consumption of slugs and snails may result in a significant divergence. Consumption of terrestrial gastropods was reported by several authors [13-21]. The percentage of this food item in the diet ranges from $0-27.2 \%$ and can be influenced by the type of habitat and the season (Table 3). It has to be mentioned 
that diet analysis studies are frequently based on scat analysis. This noninvasive method may present an error because dietary items composed of soft and highly digestible tissues (e.g., slugs) are not detected properly; thus, an underestimation may occur [22].

Table 3. The relation between habitat type and proportion of gastropods in badger diet.

\begin{tabular}{|c|c|c|c|}
\hline Country & Dominating Habitat & Percentage of Occurance & Reference \\
\hline \multirow{3}{*}{ Hungary (Komárom-Esztergom County) } & forest & 10.64 * & \multirow{3}{*}{ [13] } \\
\hline & farmland and pastures & $1.96^{*}$ & \\
\hline & forest-pasture mosaic & $12.0 *$ & \\
\hline Italy (Burano Lake Nature Reserve) & Mediterranean maquia & $3.85-18.75^{* *}$ & [14] \\
\hline Italy (Lombard Prealps) & forest & $6.2-11.1^{* *}$ & [15] \\
\hline Italy (Piedmont region) & farmland and pastures & $0.0-11.4^{* *}$ & [16] \\
\hline Poland (Bialowieza National Park) & forest & $5.6-25.0 * *$ & [17] \\
\hline Republic of Ireland & farmland and pastures & $1.0-8.0 * *$ & [18] \\
\hline \multirow{3}{*}{ Spain (southern Iberian Peninsula) } & Mediterranean maquia & $0.0-27.2 * *$ & \multirow{3}{*}{ [19] } \\
\hline & xeric shrubland & $0.0-6.6^{* *}$ & \\
\hline & forest & $0.0 * *$ & \\
\hline Spain (northern Iberian Peninsula) & forest and meadows & $15.8-27.3^{* *}$ & [20] \\
\hline Switzerland (Cantone of Berne) & farmland and pastures & $20.0 *$ & [21] \\
\hline
\end{tabular}

Badger diet composition was estimated by the analysis of stomachs and/or scats during annual $\left({ }^{*}\right)$ or seasonal $\left({ }^{* *}\right)$ investigations.

Although we did not gather information about the intermediate hosts of the $A$. daskalovi during this study, it is presumable that this species, as the other Angiostrongylus spp., involves gastropods in its life cycle as intermediate hosts [4]. Our model showed that as RH2M increases the chances for an infection decrease, while the mean intensity is connected to the proportion of grassland. Both results suggest that badger infection could be connected to terrestrial snails and slugs, which may be found in dry and open landscape habitats without extended and connected canopy. Previous malacological studies revealed the presence of 160 terrestrial gastropod species in Hungary, and more than 70 species could be found in the southwestern region [23]. Several species are strongly associated with grasslands with a moderate or very dense population [24].

We have ample evidence that some of these slugs and snails may be intermediate hosts of A. vasorum, A. andersoni, A. dujardini, and A. cantonensis [4,25-27]. To our present knowledge, A. vasorum larvae may become infectious in Deroceras agreste and Arion lusitanicus $[28,29]$. These slugs prefer the mesic open grasslands where the green, plant-based, trophic chain dominates. Due to the adaptive phenotypic plasticity, the invasive $A$. lusitanicus became a dominant species in the previous decade in this region [30]. Its fitness traits and tolerance for heat and cold may help the species to form a very dense population and thus may play a role in the life cycle of $A$. daskalovi. As for snail species, Helix pomatia can act as an appropriate intermediate host for the A. vasorum. Other species such as Vallonia pulchella, V. costata and Trichia hispida (formerly Trochulus hispidus) were described in the life cycle of other metastrongylids $[25,29,31,32]$; thus, these species may play a role in the biology of $A$. daskalovi.

However, we investigated neither the territorial behaviour of badgers nor the aggregation of potential intermediate hosts. We suggest both might be a driver of an $A$. daskalovi infection. Scent-marking is an evident element in the behaviour of badgers. They use olfactory signals to demarcate their territory and, in their hinterland, sign conspicuous landmarks, such as woodland edges, field margins and fences, etc. by shared defecation sites, the latrines [33-35]. Most of these latrines are located very close to vegetation boundaries with linear shape, which characterise grassland-dominated, mosaic-structured landscapes [36-38]. 
In the case of capable intermediate hosts, the natural landmarks may have a similar agglomerative role. A Swiss study revealed that diverse herbal field margins compared to crop margins increased the density and activity of A. lusitanicus and Deroceras spp. [39]. The authors concluded that these types of margins with their width, type and structure of vegetation cover (e.g., they contain numerous plant species and dead plant material) may contribute to an intensive presence of slugs. We suggest that the higher the proportion of overlap between the territory boundary and field margin is, the higher the prevalence and mean intensity of the parasite might be in both hosts.

\section{Conclusions}

We concluded that the morphological and molecular approach we used in this study definitely identified the $A$. daskalovi infection in Hungarian badger populations. According to the macroscopic pathological findings, this parasite showed apparently moderate impact on individual health status; thus, the determination of population-level effect needs an increased sample size. Our study may contribute to the recognition of some driving factors in the dynamics of badger infections. We deem that the results highlight possible future directions to investigate the finer linkage between definitive and possible intermediate hosts. Based on these findings, we can conclude that further investigation of intermediate hosts in different habitats is needed to discover the factors that influence the life cycle of A. daskalovi and the risk it causes for species other than badgers. The sample size of this study was not appropriate to exclude the presence of $A$. vasorum in the concerned badger population: to determine the potential epidemiological role of $A$. vasorum, more specimens should be investigated in the future.

By our molecular analysis (18s rDNA), it seems in the Angiostrongylus clade that the $A$. vasorum and $A$. daskalovi form two separated groups. These findings partly differed from others' work $[9,40]$. We deem further investigations can clarify the unsettled questions regarding the phylogenetic relationships of $A$. daskalovi.

\section{Material and Methods}

\subsection{Sample Collection}

From January 2016 to December 2020 in southwest Hungary, 50 badgers were collected to determine the presence of $A$. daskalovi (Figure 7).

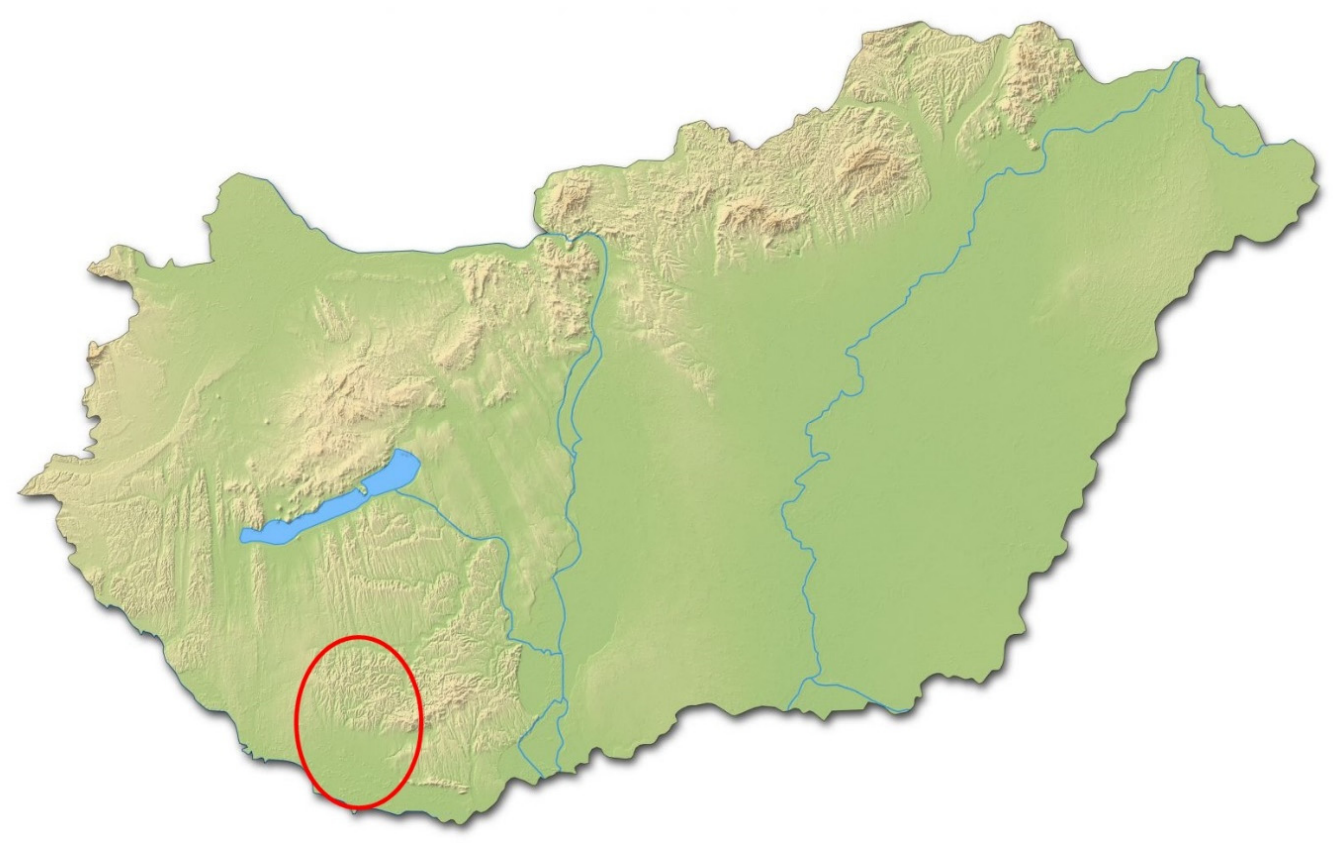

Figure 7. The studied area. 
The badgers were either legally hunted with the approval of the national control program for wildlife or were found dead due to vehicle collisions. The animals were necropsied within $24 \mathrm{~h}$ after being collected. The lung vessels and the hearts were opened and washed in $0.9 \%$ saline solution. The visible pathological lesions, especially focal inflammation, haemorrhage and fibrosis, were evaluated. The collected worms were stored in pure alcohol until their analysis.

\subsection{Parasitological and Molecular Analysis}

At first, we used a morphological approach for species identification. This process was based on the works of Janchev and Genov [7], Gerrikagoitia et al. [8], Gherman et al. [9] and Panayotova-Pencheva et al. [10]. The prevalence and mean intensity were determined with a 95\% confidence interval (CI 95\%). This analysis was carried out by using the QP web online software version 1.0.15 (http:/ / www2.univet.hu/qpweb/qp10/index.php, accessed on 11 February 2021) [41].

According to the manufacturer's protocol, genetic DNA samples were extracted using the Qiagen QIAamp DNA Mini Kit (Qiagen, Germany). Our molecular analysis was based on the nuclear $18 \mathrm{~S}$ rDNA sequences $(461 \mathrm{bp})$. For amplification, we used the primers SSU F07: 5'-AAAGATTAAGCCATGCATG-3' and SSUR09: 5'-AGCTGGAATTACCGCGGCTG$3^{\prime}$ [41]. The final volume of the reaction mix was $50 \mu \mathrm{L}$ and consisted of $25 \mu \mathrm{L}$ PCRBIO Taq Mix (PCR Biosystems, London, UK), $22 \mu \mathrm{L}$ distilled water, $1 \mu \mathrm{L}$ of each primer $(10 \mu \mathrm{M})$ and $1 \mu \mathrm{L}$ of sample DNA. The PCR cycling conditions were: denaturation at $94{ }^{\circ} \mathrm{C}$ for $2 \mathrm{~min}$, 38 cycles of denaturation at $94{ }^{\circ} \mathrm{C}$ (for $30 \mathrm{~s}$ ), annealing at $45^{\circ} \mathrm{C}$ (for $30 \mathrm{~s}$ ), and extension at $65{ }^{\circ} \mathrm{C}$ (for $60 \mathrm{~s}$ ), and a final extension cycles at $72{ }^{\circ} \mathrm{C}$ for $4 \mathrm{~min}$. The PCR products were checked by electrophoresis on $1.5 \%$ agarose gel. The product purification was carried out by Wizard SV Gel and PCR Clean-Up System (Promega, Madison, WI, USA). The sequences were analysed using ABI 3500 sequencer (Thermo Fisher Scientific, Waltham, MA, USA).

We applied 18S rDNA sequences to determine the phylogenetic relationship between Angiostrongylus spp. and other metastrongyloid taxa and to differentiate various species of Angiostrongylus genus. The phylogenetic analyses were conducted in MEGA X using the maximum likelihood method and Tamura 3-parameter model with 50\% majority rule consensus and 1000 bootstrap replications. The initial tree for the heuristic search was obtained by applying the BioNJ algorithm [42,43].

\subsection{Spatial Analysis}

Spatial autocorrelation (global and local) methods were used to detect infected and non-infected animal clusters. The global clustering analysis of the A. daskalovi was evaluated by Moran's I, and a value was calculated by using 999 permutations. In this case, the null hypothesis $\left(\mathrm{H}_{0}\right)$ stated that the infection was randomly distributed. For Moran's I determination, we used the 1.18 version of GeoDA software (https: / / geodacenter.github.io, accessed on 9 March 2021).

To assess the local spatial autocorrelation, we recorded the coordinates where the animals were found dead or shot. Local spatial clustering (LSC) of positive and negative animals was then tested by SaTScan software (version 9.6.1, www.satscan.orgvers accessed on 9 March 2021). We inserted all locations into the $2.5 \times 2.5 \mathrm{~km}$ Universal Transverse Mercator (UTM) system [44,45]. The presence of the A. daskalovi in a host meant a 'case', while the non-infected animals formed the 'control' group. The analysis also included the centre coordinate of the concerned UTM grids (Table S2). For identifying the significant spatial clusters, we used the Bernoulli Model (purely spatial). The test of significance of the identified clusters is based on a likelihood ratio test and calculated for 999 Monte Carlo simulations with the maximum cluster size of $50 \%$ of the total population for parasites [46].

\subsection{Statistical Analysis}

A binary logistic regression analysis was conducted with backward stepwise selection to determine the relation between selected biotic and abiotic variables and the prevalence of 
the $A$. daskalovi infection. We drew buffer zones around the sampling points of the infected animals $(N=36)$ with a $1.1 \mathrm{~km}$ radius [47-50]. The landcover types within the buffer zones were classified by the CORINE2018 database. We formed seven main habitat types such as urban area (URB, CLC:112), arable land (ARA, CLC: 211), grassland (GRA, CLC: 231), mixed area with similar proportion of agricultural and forest covering (MIX, CLC: 242 and 243), broad-leaved forest (BLF, CLC: 311), mixed forest (MLF, CLC: 313), shrubland (TRF, CLC: 324), and wetlands (WET, CLC: 411 and 512), and determined their proportions in each buffer zone. Climate data, namely relative humidity at $2 \mathrm{~m}$ in \% (RH2M), precipitation in $\mathrm{mm} /$ day (PREC) and temperature at $2 \mathrm{~m}$ in ${ }^{\circ} \mathrm{C}(\mathrm{T} 2 \mathrm{M})$, were collected using the sampling coordinates. For the GIS analyses, we used QGIS software [51], while the climatic data were downloaded from the POWER website (https: / / power.larc.nasa.gov / data-access-viewer/, accessed on 8 March 2021).

The explanatory variables were chosen by using the likelihood ratio test. Before the analysis, we checked the multicollinearity of the variables to eliminate highly correlated explanatory variables. We rejected the variables with the highest variance inflation factor (VIF), if the value exceeded ten [52]. Odds ratios (ORs) and their CI 95\% were used to assess the presence and strength of correspondence between the dependent and independent variables. Akaike's Information Criterion (AIC) was used for assessing different models; lower values indicated a better fitness for the data. The best model performance was assessed by using the area under the curve (AUC). We took the AUC score as a fair one if it was above 0.7. A value above 0.9 indicated that model performance is excellent [53]. The statistical analysis was conducted by SPSS version 22 [54].

During the analysis of the connection between habitat structure and mean intensity, we used the hierarchical agglomerative clustering (HAC) approach to classify all the buffer zones by their characteristics [55]. The categorisation was performed according to the BrayCurtis dissimilarity index in the PAST3 program [56,57]. The mean intensity of the groups separated by the habitat type was compared by the Kruskal-Wallis test, and differences between groups were analysed using the Mann-Whitney pairwise method. Statistical analyses were performed using the PAST3 program [57].

Supplementary Materials: The following are available online at https:/ /www.mdpi.com/article/10 $.3390 /$ pathogens $10060715 /$ s1, Table S1: Other collected nematodes from the respiratory system of badgers, Table S2: The coordinates and the parasitological status of collected badgers.

Author Contributions: E.N., T.H. and G.N. designed and performed the sample collection and parasitological analysis. I.B. and A.Z. designed and performed the molecular analysis. Á.C. and V.Á. aided in interpreting the results and worked on the manuscript. T.T. devised the project, the main conceptual ideas, and supervised the whole project. All authors have read and agreed to the published version of the manuscript.

Funding: This research was funded by „EFOP-3.4.3-16-2016-00022 QUALITAS” Development of Higher Education in Sopron, Szombathely and Tata grant and the Ministry of Human Resources (EFOP-3.6.3-VEKOP-16-2017-00005).

Institutional Review Board Statement: All specimens of this study originated from carcasses, which were harvested in the framework of a legal hunting management programme.

Informed Consent Statement: Not applicable.

Data Availability Statement: Data are contained within the article and its Supplementary Materials.

Conflicts of Interest: The authors have no conflict of interest to declare that are relevant to the content of this article.

\section{References}

1. Valente, R.; Robles, M.D.R.; Navone, G.T.; Diaz, J.I. Angiostrongylus spp. in the Americas: Geographical and chronological distribution of definitive hosts versus disease reports. Mem. Inst. Oswaldo Cruz 2018, 113, 143-152. [CrossRef]

2. Spratt, D.M. Species of Angiostrongylus (Nematoda: Metastrongyloidea) in wildlife: A review. Int. J. Parasitol. Parasites Wildl. 2015, 4, 178-189. [CrossRef] 
3. Del Robles, M.R.; Kinsella, J.M.; Galliari, C.; Navone, G.T. New host, geographic records, and histopathologic studies of Angiostrongylus spp. (Nematoda: Angiostrongylidae) in rodents from Argentina with updated summary of records from rodent hosts and host specificity assessment. Mem. Inst. Oswaldo Cruz. 2016, 111, 181-191. [CrossRef]

4. Cowie, R.H. Annotated catalogue of species of Angiostrongylus and the related genera Gallegostrongylus, Rodentocaulus and Stefanskostrongylus (Nematoda: Metastrongyloidea, Angiostrongylidae). J. Helminthol. 2019, 93, 389-423. [CrossRef]

5. $\quad$ Almeida, L.R.; Souza, J.G.R.; Santos, H.A.; Torres, E.J.L.; Vilela, R.D.V.; Cruz, O.M.S.; Rodrigues, L.; Pereira, C.A.J.; Maldonado, A., Jr.; Lima, W.D.S. Angiostrongylus minasensis n. sp.: New species found parasitizing coatis (Nasua nasua) in an urban protected area in Brazil. Rev. Bras Parasitol. Vet. 2020, 29, e018119. [CrossRef]

6. Tieri, E.; Saletti, M.A.; Pomilio, F.; Di Francesco, G.; D’Angelo, A.R.; Parisciani, G.; Troilo, M.; Morelli, D. Angiostrongylus spp. Nei Carnivori Selvatici Delle Province di Chieti e di Pescara (Italia Centrale). Poster in XVI Congresso Nazionale S.I.Di.L.V. Montesilvano. 2015. Available online: https://www.izs.it/IZS/Engine/RAServeFile.php/f/Poster/2015/Tieri_Angiostrongylus_ _spp_nei_carnivori_selvatici_2015_rev3.pdf (accessed on 17 May 2021).

7. Janchev, J.; Genov, T. Angiostrongylus daskalovi (Nematoda: Filaroididae) from Mustelidae in Bulgaria. Helminthologia 1988, 25, 81-88.

8. Gerrikagoitia, X.; Barral, M.; Juste, R.A. Angiostrongylus species in wild carnivores in the Iberian Peninsula. Vet. Parasitol. 2010, 174, 175-180. [CrossRef]

9. Gherman, C.M.; Deak, G.; Matei, I.A.; Ionică, A.M.; D'Amico, G.; Taulescu, M.; Barbu-Tudoran, L.; Sarmaşi, A.; Mihalca, A.D.; Cozma, V. A rare cardiopulmonary parasite of the European badger, Meles meles: First description of the larvae, ultrastructure, pathological changes and molecular identification of Angiostrongylus daskalovi Janchev and Genov 1988. Parasit Vectors 2016, 9 , 423. [CrossRef]

10. Panayotova-Pencheva., M.; Trifonova, A.; Dakova, V.; Salkova, D.; Movsesyan, S.O. On the parasites of genus Angiostrongylus (Nematoda: Angiostrongylidae) and some cases of Angiostrongylus daskalovi in badgers from Bulgaria. Russ. J. Parasitol. 2017, 40, 124-129.

11. Takács, A.; Szemethy, L.; Takács, A.A.; Takács, P.T.; Heltai, M. Data on the parasitological state of the Eurasian badger (Meles meles) in Hungary (in Hungarian). Magy Allatorvosok Lapja 2012, 134, 106-110.

12. Patterson, J.E.; Ruckstuhl, K.E. Parasite infection and host group size: A meta-analytical review. Parasitology 2013, 140, 803-813. [CrossRef]

13. Varga, Z.; Farkas, A. Examination of food of badger (Meles meles L) in Komárom-Esztergom county, Hungary (in Hungarian). Erdeszettud Kozl. 2016, 6, 189-197. [CrossRef]

14. Del Bove, E.; Isotti, R. The European badger (Meles meles) diet in a Mediterranean area. Hystrix 2001, 12, 19-25. [CrossRef]

15. Boesi, R.; Biancardi, C.M. Diet of the Eurasian badger Meles meles (Linnaeus, 1758) in the Natural Reserve of Lago di Piano, northern Italy. Mamm. Biol. 2002, 67, 120-125. [CrossRef]

16. Balestrieri, A.; Remonti, L.; Prigioni, C. Diet of the Eurasian badger (Meles meles) in an agricultural riverine habitat (NW Italy). Hystrix 2004, 15. [CrossRef]

17. Goszczyński, J.; Jedrzejewska, B.; Jedrzejewski, W. Diet composition of badgers (Meles meles) in a pristine forest and rural habitats of Poland compared to other European populations. J. Zool. 2000, 250, 495-505. [CrossRef]

18. Cleary, G.P.; Corner, L.A.L.; O'Keeffe, J.; Marples, N.M. The diet of the badger Meles meles in the Republic of Ireland. Mamm. Biol. 2009, 74, 438-447. [CrossRef]

19. Requena-Mullor, J.M.; López, E.; Castro, A.J.; Virgós, E.; Castro, H. Landscape influence on the feeding habits of European badger (Meles meles) in arid Spain. Mamm. Res. 2016, 61, 197-207. [CrossRef]

20. Zabala, J.; Garin, I.; Zuberogoitia, I.; Aihartza, J. Habitat selection and diet of badgers (Meles meles) in Biscay (northern Iberian Peninsula). Ital. J. Zool. 2002, 69, 233-238. [CrossRef]

21. Lüps, P.; Roper, T.; Stocker, G. Stomach contents of badgers (Meles meles L.) in central Switzerland. Mammalia 1987, 51, 559-570. [CrossRef]

22. Nielsen, J.M.; Clare, E.L.; Hayden, B.; Brett, M.T.; Kratina, P. Diet tracing in ecology: Method comparison and selection. Methods Ecol. Evol. 2018, 9, 278-291. [CrossRef]

23. Fehér, Z.; Gubányi, A. The Distribution of Hungarian Molluscs-The Catalogue of the Mollusca Collection of the Hungarian Natural History Museum; Hungarian Natural History Museum: Budapest, Hungary, 2001. (In Hungarian)

24. Uherkovich, Á.; Varga, A. Malacological examinations in the Zselic Downs, Hungary. Folia Hist. Nat. Mus Matra. 2005, 29 , 43-63. (In Hungarian)

25. Grewal, P.S.; Grewal, S.K.; Tan, L.; Adams, B.J. Parasitism of molluscs by nematodes: Types of associations and evolutionary trends. J. Nematol. 2004, 35, 146-156.

26. Kim, J.R.; Hayes, K.A.; Yeung, N.W.; Cowie, R.H. Diverse gastropod hosts of Angiostrongylus cantonensis, the rat lungworm, globally and with a focus on the Hawaiian Islands. PLoS ONE 2014, 9, e94969. [CrossRef]

27. Lange, M.K.; Penagos-Tabares, F.; Hirzmann, J.; Failing, K.; Schaper, R.; Van Bourgonie, Y.R.; Backeljau, T.; Hermosilla, C.; Taubert, A. Prevalence of Angiostrongylus vasorum, Aelurostrongylus abstrusus and Crenosoma vulpis larvae in native slug populations in Germany. Vet. Parasitol. 2018, 254, 120-130. [CrossRef] 
28. Aziz, N.A.A.; Daly, E.; Allen, S.; Rowson, B.; Greig, C.; Forman, D.W.; Morgan, E.R. Distribution of Angiostrongylus vasorum and its gastropod intermediate hosts along the rural-urban gradient in two cities in the United Kingdom, using real time PCR. Parasites Vectors 2016, 9, 56. [CrossRef]

29. Fuehrer, H.P.; Morelli, S.; Bleicher, J.; Brauchart, T.; Edler, M.; Eisschiel, N.; Hering, T.; Lercher, S.; Mohab, K.; Reinelt, S.; et al. Detection of Crenosoma spp., Angiostrongylus vasorum and Aelurostrongylus abstrusus in Gastropods in Eastern Austria. Pathogens 2020, 9, 1046. [CrossRef] [PubMed]

30. Domokos, T. Sporadic data on the mollusc fauna of Szántód (Somogy County) and its environment (in Hungarian). Bull Kaposvar Rippl-Rónai Musem 2013, 1, 71-80.

31. Lesage, C.; Patrelle, C.; Vrignaud, S.; Decors, A.; Ferté, H.; Jouet, D. Intermediate hosts of Protostrongylus pulmonalis (Frölich, 1802) and P. oryctolagi Baboš, 1955 under natural conditions in France. Parasit Vectors 2015, 8, 104. [CrossRef]

32. Deak, G.; Mihalca, A.D.; Hirzmann, J.; Colella, V.; Tăbăran, F.A.; Cavalera, M.A.; Brudașcă, F.G.; Bauer, C.; Ionică, A.M.; Alić, A.; et al. Validity of genus Perostrongylus Schlegel, 1934 with new data on Perostrongylus falciformis (Schlegel, 1933) in European badgers, Meles meles (Linnaeus, 1758): Distribution, life-cycle and pathology. Parasit Vectors 2018, 11, 568. [CrossRef]

33. Kilshaw, K.; Newman, C.; Buesching, C.D.; Bunyan, J.; Macdonald, D.W. Coordinated latrine use by European badgers, Meles meles: Potential consequences for territory defense. J. Mammal. 2009, 90, 1188-1198. [CrossRef]

34. Roper, T.; Conradt, L.; Butler, J.; Christian, S.E.; Ostler, J.; Schmid, T.K. Territorial marking with faeces in badgers (Meles meles): A comparison of boundary and hinterland latrine use. Behaviour 1993, 127, 289-307. [CrossRef]

35. Buesching, C.D.; Newman, C.; Service, K.; Macdonald, D.W.; Riordan, P. Latrine marking patterns of badgers (Meles meles) with respect to population density and range size. Ecosphere 2016, 7, e01328. [CrossRef]

36. Kruuk, H. Spatial organization and territorial behaviour of the European badger Meles meles. J. Zool. 1978, 184, 1-19. [CrossRef]

37. Feore, S.; Montgomery, W. Habitat effects on the spatial ecology of the European badger (Meles meles). J. Zool. 1999, 247, 537-549. [CrossRef]

38. Balestrieri, A.; Remonti, L.; Prigioni, C. Observations on marking behaviour in a low-density population of European badgers (Meles meles). Acta Ethol. 2011, 14, 65-68. [CrossRef]

39. Eggenschwiler, L.; Speiser, B.; Bosshard, A.; Jacot, K. Improved field margins highly increase slug activity in Switzerland. Agron. Sustain. Dev. 2013, 33, 349-354. [CrossRef]

40. Eamsobhana, P.; Lim, P.E.; Yong, H.S. Phylogenetics and systematics of Angiostrongylus lungworms and related taxa (Nematoda: Metastrongyloidea) inferred from the nuclear small subunit (SSU) ribosomal DNA sequences. J. Helminthol. 2015, 89, 317-325. [CrossRef] [PubMed]

41. Reiczigel, J.; Marozzi, M.; Fabian, I.; Rozsa, L. Biostatistics for parasitologists-A primer to Quantitative Parasitology. Trends Parasitol. 2019, 35, 277-281. [CrossRef]

42. Kumar, S.; Stecher, G.; Li, M.; Knyaz, C.; Tamura, K. MEGA X: Molecular Evolutionary Genetics Analysis across computing platforms. Mol. Biol. Evol. 2018, 35, 1547-1549. [CrossRef] [PubMed]

43. Soltis, P.S.; Soltis, D.E. Applying the bootstrap in phylogeny reconstruction. Stat. Sci. 2003, 18, 256-267. [CrossRef]

44. Kjærulff, T.M.; Ersbøll, A.K.; Gislason, G.; Schipperijn, J. Geographical clustering of incident acute myocardial infarction in Denmark: A spatial analysis approach. Spat. Spatiotemporal. Epidemiol. 2016, 19, 46-59. [CrossRef]

45. Andreasen, A.M.; Dehlendorff, P.B.; Knudtzen, F.C.; Bødker, R.; Jung Kjær, L.; Skarphedinsson, S. Spatial and temporal patterns of Lyme Neuroborreliosis on Funen, Denmark from 1995-2014. Sci. Rep. 2020, 10, 7796. [CrossRef]

46. Kulldorff, M.; Huang, L.; Pickle, L.; Duczmal, L. An elliptic spatial scan statistic. Stat. Med. 2006, 25, 3929-3943. [CrossRef]

47. Elmeros, M.; Madsen, A.B.; Prang, A. Home range of the badger (Meles meles) in a heterogeneous landscape in Denmark. Lutra 2005, 48, 35-44.

48. Remonti, L.; Balestrieri, A.; Prigioni, C. Range of the Eurasian badger (Meles meles) in an agricultural area of northern Italy. Ethol. Ecol. Evol. 2006, 18, 61-67. [CrossRef]

49. Jauker, F.; Diekötter, T.; Schwarzbach, F.; Wolters, V. Pollinator dispersal in an agricultural matrix: Opposing responses of wild bees and hoverflies to landscape structure and distance from main habitat. Landsc. Ecol. 2009, 24, 547-555. [CrossRef]

50. Balestrieri, A.; Cardarelli, E.; Pandini, M.; Remonti, L.; Saino, N.; Prigioni, C. Spatial organisation of European badger (Meles meles) in northern Italy as assessed by camera-trapping. Eur. J. Wildl. Res. 2016, 62, 219-226. [CrossRef]

51. QGIS Development Team QGIS Geographic Information System. Open Source Geospatial Foundation Project 2013. Available online: http: / / qgis.osgeo.org (accessed on 15 April 2020).

52. Marques de Sá, J.P. Applied Statistics Using SPSS, STATISTICA, MATLAB and R, 2nd ed.; Springer Publishing Company: Berlin, Germany, 2007; pp. 307-311.

53. Swets, J.A. Measuring the accuracy of diagnostic systems. Science 1988, 240, 1285-1293. [CrossRef]

54. IBM Corp. IBM SPSS Statistics for Windows; Version 22.0; IBM Corp: Armonk, NY, USA, 2013.

55. Zepeda-Mendoza, M.L.; Resendis-Antonio, O. Hierarchical Agglomerative Clustering. In Encyclopedia of Systems Biology; Dubitzky, W., Wolkenhauer, O., Cho, K.H., Yokota, H., Eds.; Springer: New York, NY, USA, 2013. 
56. Bray, J.R.; Curtis, J.T. An ordination of the upland forest communities of southern Wisconsin. Ecol. Monogr. 1957, 27, 325-349. [CrossRef]

57. Hammer, Ø.; Harper, D.A.T.; Ryan, P.D. PAST: Paleontological statistics software package for education and data analysis. Palaeontol. Electron. 2001, 4, 9. Available online: http://palaeo-electronica.org/20011/past/issue101.htm (accessed on 2 May 2020). 